\title{
The relationship between non-permanent migration and non-communicable chronic disease outcomes for cancer, heart disease and diabetes - a systematic review
}

\author{
Karen H. Wang ${ }^{1,2,3,5^{*}}$ (D), Zoé M. Hendrickson ${ }^{4}$, Cynthia A. Brandt ${ }^{3,5}$ and Marcella Nunez-Smith ${ }^{1,2}$
}

\begin{abstract}
Background: The relationship between migration and health has primarily focused on permanent migrants, although non-permanent migrants comprise a large proportion of global migrants. Non-permanent migrants may have distinct needs that affect their health outcomes. This systematic review 1) examined the evidence concerning whether nonpermanent migrants have different health outcomes than other population groups for non-communicable chronic diseases (NCDs) and 2) sought to describe how non-permanent migration is defined and measured.

Methods: For this systematic review, we developed a comprehensive search string for terms about non-permanent migration and disease and screening rates for three NCDs (cancer, heart disease, and diabetes) and searched thirteen electronic databases using the search string. Authors reviewed and evaluated articles for full-text review; hand-searched specific journals and grey literature; and scanned reference lists of relevant studies. Authors extracted and assessed data based on standard reporting for epidemiologic studies.

Results: We identified twelve peer-reviewed articles that examined NCD outcomes for non-permanent migrants as compared to other populations. Some studies showed worse or no significant differences in the NCD outcomes for non-permanent migrants compared to other groups. The articles reflected substantial diversity that exists among nonpermanent migrants, which ranged from economic migrants to nomadic populations.

Conclusion: Non-permanent migrants varied in their NCD outcomes as compared to other groups. Our included studies were heterogenous in their study designs and their definitions and measurement of non-permanent migration, which limited the ability to make conclusive statements about the health of the populations as compared to other populations. More standardization is needed in research to better understand the diversity in these populations and quantify differences in risk factors and disease rates between non-permanent migrants and other groups.
\end{abstract}

Keywords: Non-permanent migrants/migration, Geographic mobility/migration, Non-communicable chronic disease

\section{Background}

Rapid economic development has resulted in sustained global migration in the past several decades. The United Nations Development Program estimates that nearly 800 million migrants have moved permanently to either another country or another location within their own

\footnotetext{
* Correspondence: karen.wang@yale.edu

${ }^{1}$ Section of General Internal Medicine, Yale School of Medicine, PO Box 208093, New Haven, CT 06520, USA

${ }^{2}$ Equity Research and Innovation Center, Yale School of Medicine, PO Box 208093, New Haven, CT 06520, USA

Full list of author information is available at the end of the article
}

country's borders for the purpose of resettlement $[1,2]$. The impact of migration on economics and development has been a long-standing focus of the global community $[3,4]$. The spread of communicable diseases from influenza to HIV continues to highlight the public health implications of migrating communities on health and health systems [5]. In the context of an increasing global burden of non-communicable chronic diseases (NCDs) [6], migrating communities will add an additional complexity to the role of health systems in improving population health. 
The vast majority of NCD research among migrants has concentrated on identifying and addressing health needs and improving the healthcare of "permanent" migrants, i.e. immigrants (those who have resettled in another country) or rural-to-urban migrants (who have resettled within their country's border) [7, 8]. Among NCDs, research has primarily focused on cancer, cardiovascular diseases, including diabetes, as they are the leading contributors to death worldwide [9-12]. With this large body of literature, some evidence suggests immigrants have better health outcomes than local populations, known as the 'healthy migrant effect' [13]. The suggestion is that there may be a selection effect, wherein healthier migrants are more likely to immigrate to another location, and thereby have better health outcomes than the local, non-migrant population [14, 15]. Studies have demonstrated, for example, lower cardiovascular disease and risk factors among immigrants as compared to locally born populations $[13,14,16]$. In contrast, other evidence suggests that immigrants continue to have poorer outcomes compared to local populations [7, 8, 17-19], such as higher rates of diabetes among immigrants in Canada or among Afro-Caribbean immigrants as compared to non-immigrant white populations in different settings globally [20-22]. Similarly, research on rural-to-urban migrants has documented this same equivocal trend in NCD rates of disease across differing rural populations [23-25]. These differences in the burden of NCDs and their complications between permanent migrant populations and non-migrant populations are important to understand to guide necessary prevention and management strategies [26, 27].

Another large body of research focuses on identifying and reducing NCD disparities in healthcare, specifically NCD screening disparities between permanent migrants and other populations [28]. A study in Canada, for example, demonstrated varying rates of diabetes screening in immigrants, with some sub-populations of immigrants having lower screening rates than the non-immigrant population [29]. Other studies of cancer disparities have demonstrated differential rates of cancer diagnosis in immigrant populations as compared to non-immigrant populations. Furthermore, many studies have demonstrated lower rates of cancer screening among immigrant populations as compared to other population groups [30,31].

As migration is a dynamic process not often captured by literature on permanent migrants, there is a need to better understand the sub-populations often aggregated into the category of "migrants" [32]. Some researchers have explored migration-related attributes beyond permanent migration and their relationship to NCD outcomes to shed light on health differences between migrant populations and other populations [2, 33-35]. These attributes include, but are not limited to, length of time outside of place of origin; distance from place of origin; or the unit of migration (e.g., an individual or an entire family) [36]. Type of migration, other than "permanent" migration, is also a migration-related attribute that can influence health outcomes [36-45]. The "non-permanent" migrant populations (such as those who are temporary, circular, return, or double-leap/secondary migrants) are important to examine because: 1) with globalization, the volume of "non-permanent" migrant population is likely to grow; and 2) they likely represent a heterogeneous population who are at risk for NCDs $[32,38,46]$.

We hypothesized that non-permanent migrants would have higher rates of disease and lower rates of chronic disease screening, as the dynamic livelihoods of nonpermanent migrants may be a signal of greater vulnerability as compared to other migrant populations, based on World Health Organization conceptual model for the influence of social and structural determinants of health on the health of individuals [47]. Different than permanent migrants, the geographic mobility of nonpermanent migrants may be a manifestation of the influence of contextual factors in different localities (such as discrimination, legal status, economic opportunity, available housing, etc.) and may independently affect health and healthcare outcomes, positively or negatively. The identification of greater rates of disease in non-permanent migrant populations as compared to other populations is essential to inform strategies to prevent and manage NCDs for these populations across geographic contexts. Moreover, identification of lower rates of screening in non-permanent migrant populations would necessitate a reassessment of the delivery of healthcare services to these populations.

As a step to advancing scientific understanding of these populations and their healthcare needs, we conducted a systematic review focused on the health of non-permanent migrants. Specifically, we examined the literature to compare non-permanent migrants to other populations for the NCDs, specifically cancer, heart disease, and diabetes, which are the main NCD contributors to mortality globally [9-12]. We were interested in rates of disease and screening as initial steps to understating health and healthcare needs. Since we anticipated variation in how non-permanent migrant populations were described in the literature, we also sought to describe how non-permanent migration was defined and measured.

\section{Methods}

\section{Search string}

We developed a comprehensive search string to identify articles measuring the relationship between non-permanent migration and disease and screening rates for three noncommunicable diseases: cancer, heart disease, and diabetes 
Table 1 Examples of keywords and Boolean operators used in electronic database searches

\begin{tabular}{|c|c|c|c|c|c|c|}
\hline Or $\downarrow$ & $<$ Migration $>$ & $<$ Cancer $>$ & Or $\rightarrow$ & $<$ Heart Disease $>$ & Or $\rightarrow$ & $<$ Diabetes $>$ \\
\hline & \multicolumn{6}{|l|}{ Subject headings } \\
\hline & Human migration ${ }^{a}$ & \multirow[t]{6}{*}{ Neoplasms $^{\mathrm{a}}$} & & \multirow[t]{6}{*}{ Heart Diseases ${ }^{\mathrm{a}}$} & & \multirow[t]{6}{*}{ Diabetes Mellitus ${ }^{\mathrm{a}}$} \\
\hline & Emigrants and immigrants ${ }^{\mathrm{a}}$ & & & & & \\
\hline & Transients and migrants ${ }^{\mathrm{a}}$ & & & & & \\
\hline & Residential Mobility ${ }^{\mathrm{b}}$ & & & & & \\
\hline & Migrant/foreign worker ${ }^{c}$ & & & & & \\
\hline & Medical Tourism/Travel medicine ${ }^{a}$ & & & & & \\
\hline & \multicolumn{6}{|c|}{ Text words (concepts to cover different types of migration by attributes) } \\
\hline & Geography & \multirow[t]{2}{*}{ Tumor } & & \multirow[t]{2}{*}{ Cardiovascular disease } & & \multirow[t]{6}{*}{ Diabet* $^{*}$} \\
\hline & $\begin{array}{l}\text { - Borders/Cross-border } \\
\text { - Bi/transnational } \\
\text { - Rural/urban } \\
\text { - Regional }\end{array}$ & & & & & \\
\hline & Patterns/Frequency & \multirow[t]{2}{*}{ Cancer } & & \multirow[t]{2}{*}{ Ischemic heart disease } & & \\
\hline & $\begin{array}{l}\text { - Return } \\
\text { - Temporary } \\
\text { - Regular } \\
\text { - Circular }\end{array}$ & & & & & \\
\hline & Populations & \multirow[t]{2}{*}{ Carcino*/Onco* } & & \multirow[t]{2}{*}{ Myocardial Infarction } & & \\
\hline & $\begin{array}{l}\text { - Mobile } \\
\text { - Floating } \\
\text { - Seasonal } \\
\text { - Worker/farmworker }\end{array}$ & & & & & \\
\hline
\end{tabular}

${ }^{a}$ Medline subject heading. Similar subject headings were found and used in other databases where available

${ }^{b} \mathrm{CINAHL}$ subject heading. Similar subject headings were found and used in other databases where available

${ }^{c}$ Embase subject heading. Similar subject headings were found and used in other databases where available

(Table 1). Search terms for non-permanent migration included variations of terms that describe the process of migration, attributes related to migration, populations who migrate, and the main non-communicable diseases of interest.

We identified relevant studies by searching thirteen electronic databases using the developed search string, hand-searching specific journals and grey literature, and scanning reference lists of relevant studies. We adapted the developed search string for the following databases: Medline, Embase, Global Health, PsychInfo, EBSCO, CINAHL, Africa-Wide NiPad, Sociological Abstracts, Social Services Abstracts, EconLit, IBSS, Latin American and Caribbean Health Sciences Literature Database, and Social Science Citation Index (See supplemental appendix for detailed search string for each database). We hand-searched migration-specific journals that were not indexed in the above databases, including Asian and Pacific Migration Journal, International Migration Review, Journal of Borderland Studies, and Journal of Ethnic and Migration Studies. Articles that cited relevant articles were also hand-searched according to inclusion and exclusion criteria. Lastly, we developed a comprehensive list of relevant organizations' websites and searched for grey literature according to inclusion and exclusion criteria (available upon request).

\section{Inclusion and exclusion criteria}

We retrieved articles published or released between January 1, 2003 and June 19, 2015, with titles and abstracts available in English. We reviewed all full texts available in English, Spanish, French, and Chinese. We included full-text articles with experimental and observational study designs. Full text articles eligible for final review included: 1) adults aged 18 years and older; 2) non-permanent migrants; 3 ) comparisons between a non-permanent migrant population and another population; 4) at least one non-communicable disease of interest, specifically diabetes, cardiovascular disease, or cancer; and 5) at least one measure of NCD outcome, i.e. disease or screening rates of three NCDs (prevalence or incidence measures).

For this study, to distinguish from a definition of permanent immigration used in peer-reviewed literature describing a lasting change in usual residence, we defined a non-permanent migrant as someone who had more than one movement across a border, suggesting a non-lasting residence [48, 49]. The term migrant is "understood to cover all cases where the decision to migrate was taken freely by the individual concerned for reasons of 'personal 
convenience' and without intervention of an external compelling factor, moving to another country or region to better their material or social conditions and improve the prospect for themselves or their family" [50]. Based on this definition, we excluded studies on refugees and asylum seekers. We further excluded undocumented migrants due to the unique barriers to care and health outcomes often experienced by these populations.

\section{Study selection}

Once articles were pulled, we removed duplicate documents from the different databases. Two authors in an un-blinded systematic process evaluated the eligibility of abstracts for full-text review. They independently evaluated a sample of 100 abstracts to ensure the inter-rater reliability based on the inclusion and exclusion criteria (91\% agreement). In the event of arbitration, the full text was pulled for further review.

Both reviewers extracted data independently from the final list of articles based on a pre-defined extraction form. For assessment, we adapted tools from the STROBE reporting for epidemiologic studies and Downs and Black [8, 51, 52]. We assessed each article for 1) completeness, based on the 22-item checklist from the STROBE, and 2) quality, based on an 11-item checklist from the Downs and Black tool [51]. The 22-item checklist assessed the information present in the title, abstract, background, methods, results, discussion, and funding reported by the authors. The 11-item checklist assessed quality by measuring risk of bias in external and internal validity [51]. The two authors scored the final set of articles independently and then averaged the scores.

\section{Results}

The search of databases provided a total of 11,492 citations (Fig. 1). Our review of grey literature and non-indexed journals resulted in zero papers for inclusion. Twelve articles met our inclusion criteria [40, 53-63]. The number of abstracts and full texts reviewed at each stage are shown in Fig. 1.

\section{Synthesis of results}

\section{General description of included studies}

The 12 studies reflected a range of non-permanent migrant groups examined and study designs in the peer-reviewed literature (Table 2) [40, 53-63]. The non-permanent migrant groups examined included: three studies on migrant farmworkers in in the United States, who traveled across regions with the growing seasons [54-56]; one study on female non-local sex workers who had temporary visas to live in Hong Kong, China [63]; four studies on nomadic populations (the Traveller population in Ireland and the United Kingdom and Mongolian pastoralists) [58-61]; three studies of return migrants in Mexico, who had moved from
Mexico the United States and at some point returned back to Mexico [40, 53, 62], and one study on repatriates in Norway [57]. Eleven studies had a cross-sectional design $[40,53-56,58-63]$, and one study was a retrospective cohort study [57].

\section{Outcomes of interest \\ Prevalence/incidence rates of NCD}

Among the 12 studies comparing non-permanent migrant population to at least one other population, one article examined differences in prevalence rates of cancer, heart disease, and diabetes [60]; two articles, heart disease and diabetes $[40,58]$; one, cancer incidence only [57], two articles, heart disease only [59,61], and three articles, diabetes only [53, 54, 62],

Parry et al. examined three health outcomes of the non-permanent Traveller population as compared to age and sex-matched individuals (who were either ethnic minority, low socioeconomic or non-urban populations) [60]. In bivariate analyses, this study demonstrated higher heart disease in the non-permanent Traveller population as compared to the comparison group (prevalence: $8 \%$ vs $4 \%, p<0.05$ ), but it found no differences in rates of diabetes or cancer between the groups [60]. McGorrian et al. compared rates of heart disease and diabetes in another Traveller population to a general population and found no significant difference between self-reported rates of heart disease but did find a significant difference in diabetes rates $(10.9 \%$ vs. $4.6 \%, p<0.001)$ [58]. Ullmann et al. compared self-reported heart disease and diabetes between non-migrants in Mexico and non-permanent return migrants to/from Mexico and United States [40]. The non-permanent return migrants were significantly more likely to report heart disease than non-migrants $(6.9 \%$ vs $3.6 \%, p<0.05)[40]$.

The retrospective cohort study by Kristensen et al. examined cancer incidence among a nationally representative sample of residents in Norway across three groups (non-migrants, emigrants, and repatriates) and demonstrated no statistical difference in cancer incidence between non-migrants and non-permanent repatriates [57].

Studies by Aguila et al. and Riosmena et al. showed no difference in the odds of self-reported diabetes when comparing return migrants to two other population groups (non-migrants who remained in Mexico and immigrants in the United States from Mexico) [53, 62].

\section{Screening rates of NCDs}

Three studies measured breast and cervical cancer screening rates among non-permanent migrants compared to another population group [55, 56, 63]. Studies by Castenada et al. and Knoff et al. comparing non-permanent migrant farmworkers to seasonal farmworkers in the United States (i.e. as those who lived in one place and worked as 


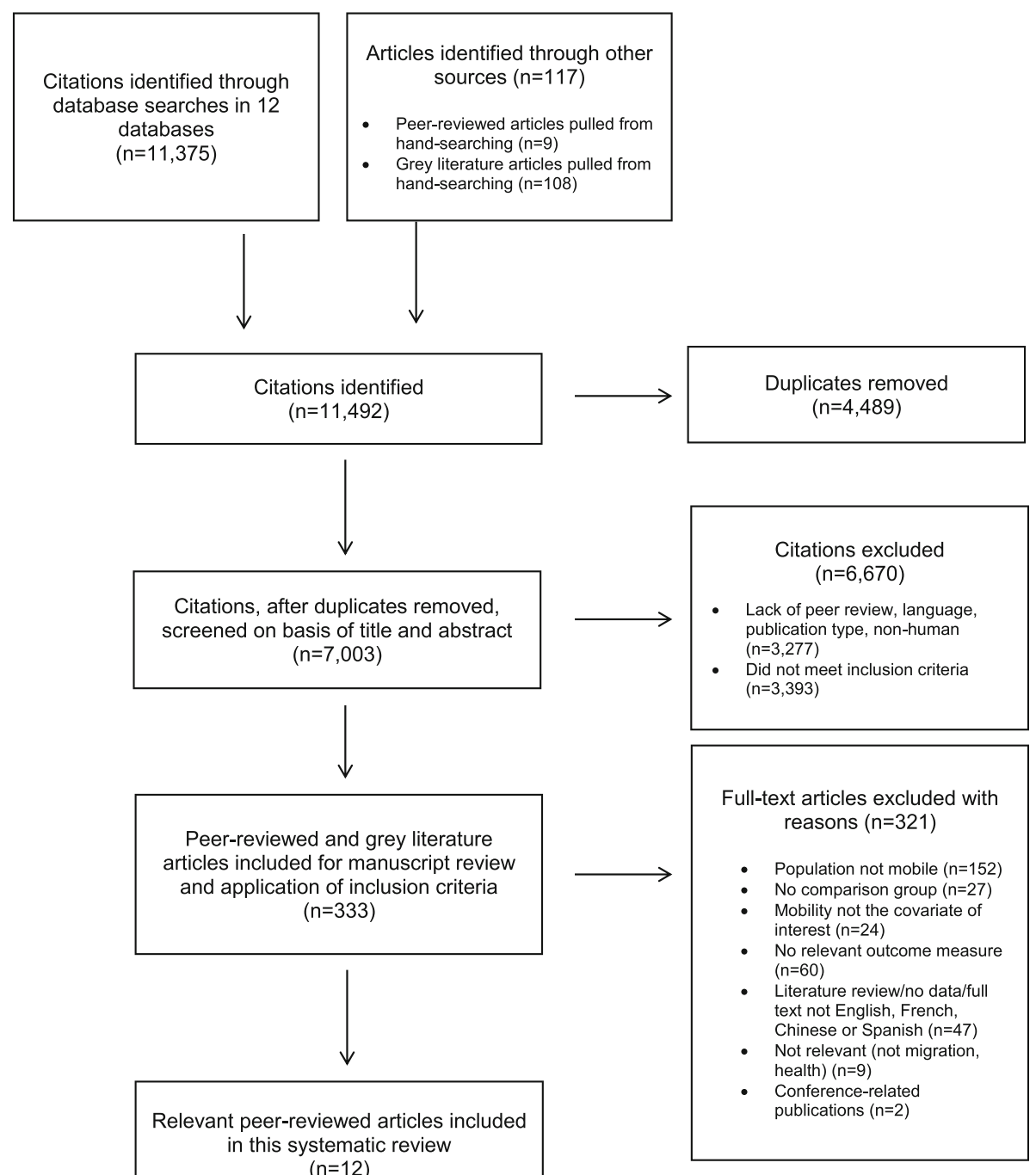

Fig. 1 Flow Diagram

farmworkers during the harvest season) demonstrated similar rates of cervical cancer screening between population groups [55, 56]. However, in the same Castenada et al. study, the screening mammography rates were significantly lower in the non-permanent migrant farmworkers as compared to the seasonal farmworkers $(70.6 \%$ vs $100 \%, p<$ 0.01 ) [55]. Wong et al. compared non-permanent migrant female sex workers (i.e. those who had a temporary visa status) to other female sex workers in Hong Kong, China, demonstrating that the non-permanent migrant female sex workers were less likely to have had a pap smear and were more likely to have abnormal pap smear results than other female sex workers [63].

\section{Definition and measurement of non-permanent migration} Definitions and measurement of non-permanent migration varied across studies. The majority of studies identified or assumed a person's "migration status" based on movement across geographic borders (often international or intra-national borders) and traveling from one place to another location and living in this other location. For example, Kristensen et al. used terms related to movement across national borders, and groups of migrants were categorized as non-emigrants, emigrants, and repatriates [57]. Several studies, including Aguila et al., Riosmena et al., and Ullmann et al., used the term, "return migrants," and Ullmann et al.'s study specifically defined "return or returned migrants" as "those in the sample that have previous migration experience to the U.S. but are in Mexico at the time of survey" [40, 53, 62]. In Castaneda et al. and Knoff et al., as described above, migrant status was based on a designation given by a governmental body, differentiating two different types of farmworkers based on the geographic mobility of one group (migrant farmworker) as compared to 







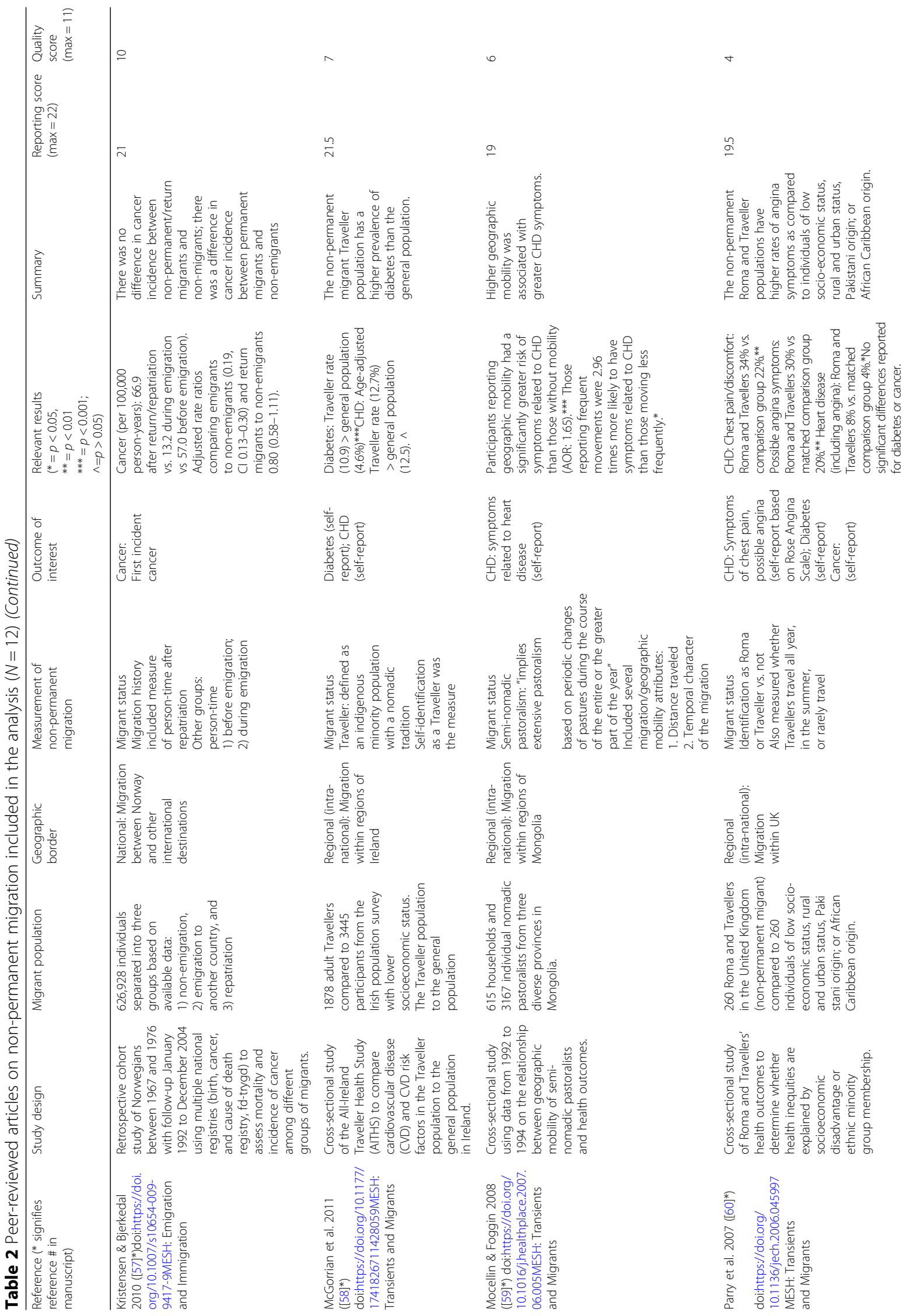




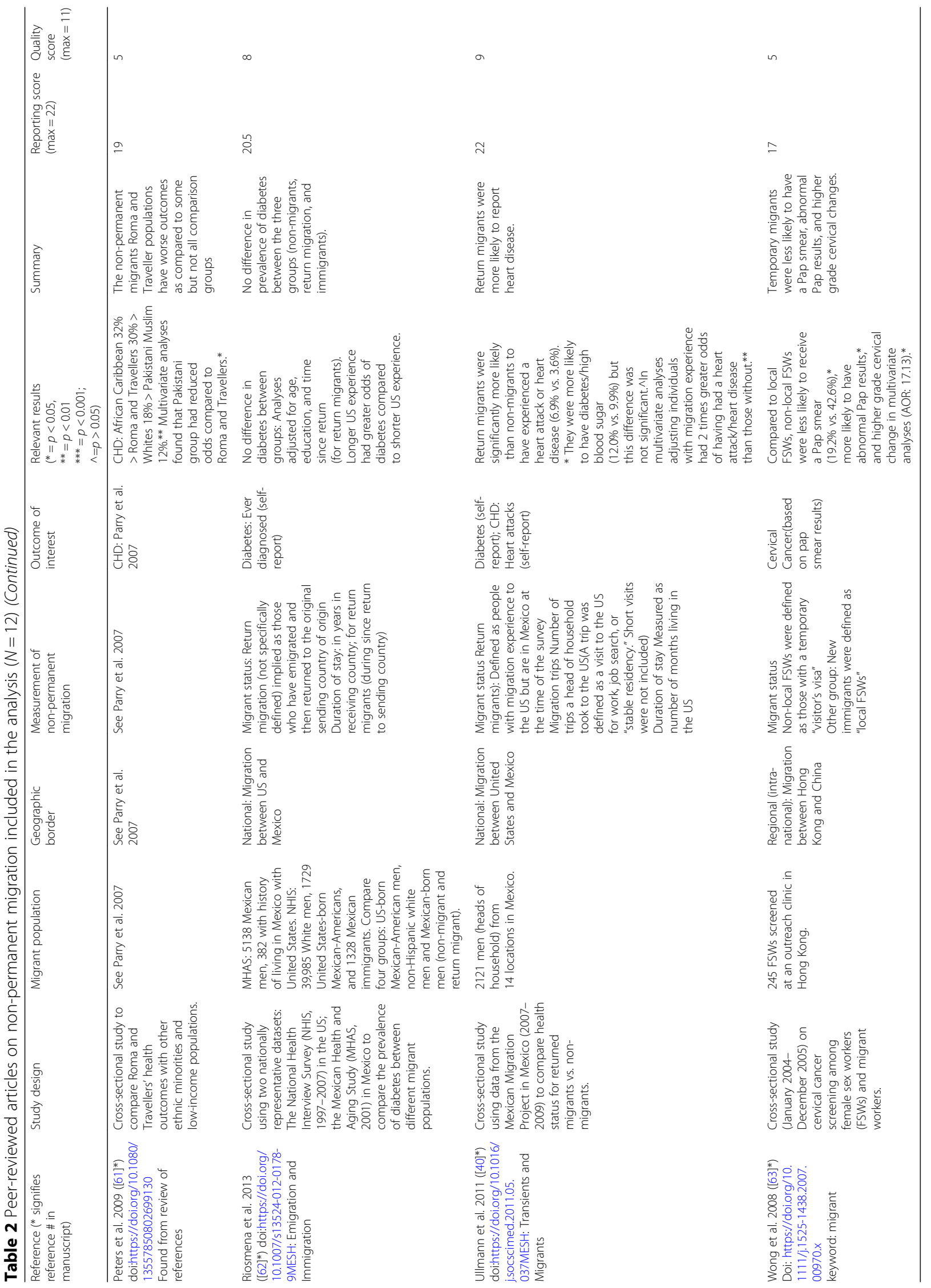


farmworkers "who live in one place" (seasonal farmworker) $[55,56]$. Similarly, Wong et al. defined their migrant groups based on a legal definition, as determined by a person's visa that determined length of stay [63]. A few studies expanded beyond identifying "migrant status" and measured distance traveled or discrete counts of crossing a regional or national border $[57,59,62]$.

\section{Study quality}

Of the 12 studies, the completeness of reporting based on the STROBE 22-item checklist ranged from 15.5 to $22[40,53-63]$. The quality of the studies, based on an 11-item checklist from the Downs and Black tool, ranged from 4.5 to 10 , with lower scores most often due to poor generalizability to other populations because sampling was not representative of the entire population of interest. Moreover, 11 of the 12 included studies were cross-sectional design $[40,53-56,58-63]$, among which only three studies clearly indicated how missing data might have affected study findings to address possible issues with confounding $[56,58,62]$.

\section{Discussion}

This systematic review of the literature found 12 studies that compared non-permanent migrants with another population to examine differences in NCD outcomes for cancer, heart disease, and diabetes. Our main finding was that NCD outcomes of non-permanent migrants were similar to or worse than other populations. However, these equivocal findings likely reflect other important conclusions of this review, such as the heterogeneity of 1) study designs, 2) non-permanent migrant groups by migration attributes and 3) spatial and temporal measurements of migration.

Some studies found significant differences in NCD prevalence between non-permanent migrant populations and other population groups. For example, of the four studies on heart disease, all documented higher rates of self-reported heart disease among the non-permanent migrants as compared to other groups [58-61]. In contrast, of the five studies on diabetes, only one study demonstrated that non-permanent migrants had higher prevalence than other non-migrant groups; the other studies showed no difference [40, 53, 54, 58, 62]. In light of the variation in study designs, measurements, and research contexts, it is challenging to make strong conclusions about differences between non-permanent migrant groups and other population groups. However, differences within non-permanent migrant groups and between these groups and others likely exist, as past literature on permanent migrants suggests multifactorial influences on disease risk including genetics, environmental exposures, and social-behavioral factors [35, 64]. For non-permanent migrants, we expect there may be factors affecting health risk and outcomes, complicated by the additional influence of having resided in different geographies, with varying numbers of movements, over different periods of time. Non-permanent migrants may also have social and family ties across geographies that influence health risks and outcomes [45, 65-68]. However, the strength of these ties may differ as a result of varying migration attributes, such as the migration unit (i.e. the individual or family), distance from one's network, cultural identities and broader socioeconomic dynamics in countries of origin [69-71]. We infer that these contextual and social-level factors in these different geographies confer unique risks and opportunities that affect an individual's health [38, 72-74]. Future work should investigate the influence of these factors on the health behaviors and practices of non-permanent migrants in different geographic locations.

The included studies represented diverse migrant populations in their motivations and their migration-related spatial and temporal attributes. For example, the studies represented a broad range of motivations that led to an individual's non-permanent migrant status, including for labor reasons (e.g. farmworkers) and lifestyle (e.g. nomadic populations), that would affect outcomes [54-56, 58-61]. The geographic borders crossed were both regional and national and are important to identify and understand, as living in one context or another confers different opportunities and challenges for migrants. Moreover, if measured, the time period for the measurement of migration ranged from seasonal to discrete counts of a migration event $[40,57,59,60]$. This issue has been discussed in migration literature, where the temporal attributes of migration such as frequency, duration, and timeframe are not consistently measured, thereby hindering opportunities for generalization and comparison in migration research [75].

A review of how the included were indexed within the bibliographic databases suggests a need for more granular and standardized vocabulary around non-permanent migration. Three of the 12 articles were retrieved from keyword searches with use of the terms "migrant" or "farmworker" [54, 55, 63], eight were retrieved based on their categorization into the broad medical subject headings like "Emigration and Immigration" and "Transients and Migrants" [40, 53, 56-59, 61, 62]. These findings are consistent with the broad International Office for Migration (IOM) definition of migration [2, 76]. A few other definitions exist that may serve to provide a framework for this population, but these are also limited. For example, per IOM, a short-term migrant is "a person who moves to a country other than that of his or her usual residence for a period of at least three months but less than a year, except in cases where the movement to that country is for purposes of recreation, holiday, visits to friends or 
relatives, business or medical treatment" [50, 77]. This definition excludes migrants who are regionally mobile within national geographic borders, those who may remain in one locality for more than one year, or those who have no usual residence. Refinement and standardization of the language used to describe non-permanent migration will enable further examination of the health behaviors and health outcomes of these populations.

There are several limitations to this systematic review. Our own a priori definition of "non-permanence" based on the number of moves across a border suggesting a non-lasting residence is a limited, but important, facet of non-permanence. Our premise was that these individuals were geographically mobile, and therefore may also be residentially mobile, to differentiate from the concept of "permanent" migrant whose definition is tied to having a usual residence. However, the concept of residence/ residential mobility limits our understanding of non-permanence. 'Residence' is less central to the concept of non-permanent migration as compared with permanent migration, as non-permanent migrants may have no usual residence or no residence at all [49]. The definition utilized here demands further development and investigation to capture the diversity of different non-permanent migrant populations, to highlight the different motivations for migration, and to better understand the influence of contextual factors in different locations. However, these findings reflect the current limitations and challenges in this field of study, where there is wide variation in vocabulary, definitions, and measurement across disciplines and limited availability of data [35]. Article quality of included studies also varied and limited the ability to generalize or make inferences about the relationship between non-permanent migration as compared to other populations and NCD disease and screening rates. As prior research studies have noted, variations in terminologies, design, and quality challenges comparisons across studies and underscores the need of further systematization to establish standards of practice [35].

The limited number of studies on non-permanent migrants is not surprising. Some studies on non-permanent migrant populations (such as labor migrants, nomadic populations, and farmworkers) that were excluded from our final analysis did not include a comparison group [78-83]. Each migrant population has distinct individual and societal factors that influence health and health outcomes, which makes finding an appropriate comparison group challenging $[35,84]$. The limited number of studies on non-permanent migrants from low- or middle-income countries likely reflects our inclusion criteria, such as requiring a comparison group or outcomes of interest [59, $81,85,86]$. Though it is possible we did not capture all articles for inclusion into our review because of the diversity of terms for migration, to minimize this possibility, we created a comprehensive search string, reviewed articles in the references list of included articles, and reviewed relevant grey literature. Moreover, our analysis focused on cancer, heart disease, and diabetes, yet non-permanent migrants are affected by other non-communicable diseases, such as chronic obstructive lung diseases and obstetric diseases, that are influenced by social and structural determinants of health $[87,88]$. Future work can investigate these populations in low- and middle-income countries and expand outcomes of interest.

More standardized measurements for the spatial and temporal attributes of non-permanent migration and explicit documentation of definitions are needed $[57,59,62]$. Consistent use of a multilevel framework for migration may inform standardization of variable selection and definitions used. In peer-reviewed literature on permanent migrants, several conceptual models have been used to define variables that influence individuals' health outcomes [89-91]. These models could be adapted for research on non-permanent migrants to account for the multiple contexts in which non-permanent migrants have lived and how these contexts influence their health and health seeking behaviors. Researchers could also begin to consistently use the term "non-permanent" to describe these populations in distinct contrast to permanent migrants. With greater standardization, we can then incrementally build upon the limited knowledge about the different typologies of non-permanent migration, advance the science around migrating populations, and improve public health systems' abilities to plan for and care for these populations.

\section{Conclusion}

The confluence of non-permanent migration in the context of the growing burden of NCDs is an important area of investigation that requires greater examination. As research examining non-permanent migrants' health grows, standardized vocabulary, definitions, and measurements of migration attributes are key mechanisms for organizing data to facilitate indexing and synthesis of results across multiple contexts. This work has implications not only for the health of migrant populations but also for the public health systems that care for these populations. Currently, health prevention, screening, and treatment protocols may vary across these locations, and health information about these non-permanent populations is not often accessible in different regional or international areas [92, 93]. Public health and healthcare systems may need to develop different strategies to minimize health risks of NCDs for non-permanent migrants across geographies.

\section{Abbreviations}

IOM: International Organization for Migration; NCDs: non-communicable chronic diseases 


\section{Acknowledgements}

The authors acknowledge Janis Glover, MLS, Harvey Cushing/John Hay Whitney Medical Library, Yale University School of Medicine, for her review of our search criteria and extraction methodology, and Hannah Friedman, BA, and Emma Tran, BS, for editing assistance.

\section{Funding}

At the time of the study, KW, ZH, MNS were supported in part by U24 MD006938 from the National Institute on Minority Health and Health Disparities. KW also was also supported by Veterans Affairs Office of Academic Activities Fellowships. This publication was also made possible by CTSA Grant Number KL2 TR001862 from the National Center for Advancing Translational Science, a component of the National Institutes of Health. The funders had no role in the design or conduct of the study. Views expressed are those of the authors and do not represent those of the funding source.

\section{Availability of data and materials}

Data and materials can be requested.

\section{Authors' contributions}

$\mathrm{KW}, \mathrm{ZH}, \mathrm{CB}$, and MNS contributed to the design and concept of the paper and substantive review of the manuscript. KW and ZH collected, analyzed and summarized the data. KW prepared the first full draft of the manuscript. All authors have read the manuscript and approved the final manuscript.

\section{Ethics approval and consent to participate}

Not applicable.

\section{Consent for publication}

Not applicable.

\section{Competing interests}

The authors declare that they have no competing interests.

\section{Publisher's Note}

Springer Nature remains neutral with regard to jurisdictional claims in published maps and institutional affiliations.

\section{Author details}

${ }^{1}$ Section of General Internal Medicine, Yale School of Medicine, PO Box 208093, New Haven, CT 06520, USA. 'Equity Research and Innovation Center, Yale School of Medicine, PO Box 208093, New Haven, CT 06520, USA.

${ }^{3}$ Veterans Affairs Connecticut Healthcare System, West Haven, CT, USA. ${ }^{4}$ Health, Behavior and Society Department, John Hopkins Bloomberg School of Public Health, Baltimore, MD, USA. ${ }^{5}$ Center for Medical Informatics, Yale School of Medicine, New Haven, CT, USA.

\section{Received: 30 June 2018 Accepted: 11 March 2019}

\section{Published online: 15 April 2019}

\section{References}

1. United Nations Development Programme. Overcoming barriers: human mobility and development. In. UNDP Human Development Report Office: New York; 2009

2. International Organization for Migration. Glossary on Migration. In: International Migration Law No 25; 2011.

3. International Organization for Migration: World Migration 2008: Managing Labour Mobility in the Evolving Global Economy. In., vol. VOLUME 4; 2008.

4. International Organization for Migration: The World Migration Report 2010: The Future of Migration: Building capacities for change. In.; 2012.

5. Helble M. The movement of patients across borders: challenges and opportunities for public health. Bull World Health Organ. 2011;89(1):68-72.

6. World Health Organization: Global action plan for the prevention and control of noncommunicable diseases 2013-2020. 2013.

7. Chin MH, Walters AE, Cook SC, Huang ES. Interventions to reduce racial and ethnic disparities in health care. Med Care Res Review. 2007:64(5 Suppl):7S-28S.

8. Peek ME, Cargill A, Huang ES. Diabetes health disparities: A systematic review of health care interventions. Med Care Res Review. 2007;64(5 Suppl): 101S-56S

9. Vos $\mathrm{T}$, Abajobir AA, Abate KH, Abbafati C, Abbas KM, Abd-Allah F, et al. Global, regional, and national incidence, prevalence, and years lived with disability for 328 diseases and injuries for 195 countries, 19902016: a systematic analysis for the global burden of disease study 2016. Lancet. 2017;390(10100):1211-59.

10. Wang $H$, Abajobir AA, Abate $K H$, Abbafati C, Abbas KM, Abd-Allah F, et al. Global, regional, and national under-5 mortality, adult mortality, age-specific mortality, and life expectancy, 1970-2016: a systematic analysis for the global burden of disease study 2016. Lancet. 2017;390(10100):1084-150.

11. World Health Organization. Global action plan for the prevention and control of noncommunicable diseases 2013-2020. 2013. https://www.who. int/nmh/events/ncd_action_plan/en/

12. Naghavi M, Abajobir AA, Abbafati C, Abbas KM, Abd-Allah F, Abera SF, et al. Global, regional, and national age-sex specific mortality for 264 causes of death, 1980-2016: a systematic analysis for the global burden of disease study 2016. Lancet. 2017;390(10100):1151-210.

13. Crimmins EM, Kim JK, Alley DE, Karlamangla A, Seeman T. Hispanic paradox in biological risk profiles. Am J Public Health. 2007;97(7):1305-10.

14. Rasulo D, Spadea T, Onorati R, Costa G. The impact of migration in all-cause mortality: the Turin longitudinal study, 1971-2005. Soc Sci Med. 2012;74(6): 897-906.

15. Lu Y. Test of the 'healthy migrant hypothesis': a longitudinal analysis of health selectivity of internal migration in Indonesia. Soc Sci Med. 2008;67(8):1331-9.

16. Blue L, Fenelon A. Explaining low mortality among US immigrants relative to native-born Americans: the role of smoking. Int J Epidemiol. 2011:40(3): 786-93.

17. Abraido-Lanza AF, Dohrenwend BP, Ng-Mak DS, Turner JB. The Latino mortality paradox: a test of the "salmon bias" and healthy migrant hypotheses. Am J Public Health. 1999;89(10):1543-8.

18. Stephenson R, Argeseanu S, Oza-Frank R, Hutcheson M, Narayan KM. Cardiometabolic risk among the foreign-born population in the United States: new pathways for innovative research and health policy. Ethn Dis. 2008;18(3):277.

19. Barcellos SH, Goldman DP, Smith JP. Undiagnosed disease, especially diabetes, casts doubt on some of reported health 'advantage' of recent Mexican immigrants. Health Aff. 2012;31(12):2727-37.

20. Adhikari R, Sanou D. Risk factors of diabetes in Canadian immigrants: A synthesis of recent literature. Can J Diabetes. 2012;36(3):142-50.

21. Banerjee A, Shah B. Differences in prevalence of diabetes among immigrants to Canada from south Asian countries. Diabet Med. 2018:35(7): 937-43. Epub 2018 May 3.

22. Bennett NR, Francis DK, Ferguson TS, Hennis AJ, Wilks RJ, Harris EN, MacLeish MM, Sullivan LW. Disparities in diabetes mellitus among Caribbean populations: a scoping review. Int J Equity Health. 2015;14(1):23.

23. Eberhardt MS, Pamuk ER. The importance of place of residence: examining health in rural and nonrural areas. Am J Public Health. 2004;94(10):1682-6.

24. Zaman MJS, de Mola CL, Gilman RH, Smeeth L, Miranda JJ. The prevalence of angina symptoms and association with cardiovascular risk factors, among rural, urban and rural to urban migrant populations in Peru. BMC Cardiovasc Disord. 2010;10(1):50.

25. Batsis JA, Whiteman KL, Lohman MC, Scherer EA, Bartels SJ. Body Mass Index and Rural Status on Self-Reported Health in Older Adults: 20042013 Medicare Expenditure Panel Survey. The Journal of Rural Health. 2018 Feb;34:556-64.

26. Abraído-Lanza AF, Armbrister AN, Flórez KR, Aguirre AN. Toward a theorydriven model of acculturation in public health research. Am J Public Health. 2006;96(8):1342-6.

27. Viruell-Fuentes EA, Morenoff JD, Williams DR, House JS. Contextualizing nativity status, Latino social ties, and ethnic enclaves: an examination of the 'immigrant social ties hypothesis'. Ethn Health. 2013;18(6):586-609.

28. Chin MH, Walters AE, Cook SC, Huang ES. Interventions to reduce racial and ethnic disparities in health care. Los Angeles: SAGE Publications Sage CA; 2007.

29. Borkhoff CM, Saskin R, Rabeneck L, Baxter NN, Liu Y, Tinmouth J, Paszat LF. Disparities in receipt of screening tests for cancer, diabetes and high cholesterol in Ontario, Canada: a population-based study using area-based methods. Can J Public Health. 2013;104(4):284-90.

30. Masi CM, Blackman DJ, Peek ME. Interventions to enhance breast cancer screening, diagnosis, and treatment among racial and ethnic minority women. Med Care Res Review. 2007;64(5_suppl):195S-242S.

31. Lu M, Moritz S, Lorenzetti D, Sykes L, Straus S, Quan H. A systematic review of interventions to increase breast and cervical cancer screening uptake among Asian women. BMC Public Health. 2012;12(1):413. 
32. Abubakar I, Devakumar D, Madise N, Sammonds P, Groce N, Zimmerman C, Aldridge RW, Clark J, Horton R. UCL-Lancet Commission on migration and health. Lancet. 2016;388(10050):1141-2.

33. Massey DS. Immigration statistics for the twenty-first century. Ann Am Acad Pol Soc Sci. 2010;631(1):124-40.

34. Abel GJ, Sander N. Quantifying global international migration flows. Science. 2014;343(6178):1520-2

35. Schenker MB, Castañeda X, Rodriguez-Lainz A. Migration and health: a research methods handbook: Univ of California press; 2014

36. Taylor B, Garduo LS, Reyes E, Valio R, Rojas R, Donastorg Y, Brudney K, Hirsch J. HIV care for geographically mobile populations. Mount Sinai J Med New York. 2011;78(3):342-51.

37. Horton S, Cole S. Medical returns: seeking health care in Mexico. Soc Sci Med. 2011;72(11):1846-52.

38. Vertovec S. Circular migration: the way forward in global policy? In: International Migration Institute; 2007.

39. Sinatti G. 'Mobile Transmigrants' or 'Unsettled Returnees'? Myth of return and permanent resettlement among Senegalese migrants. Popul Space Place. 2011;17(2):153-66.

40. Ullmann SH, Goldman N, Massey DS. Healthier before they migrate, less healthy when they return? The health of returned migrants in Mexico. Soc Sci Med. 2011;73(3):421-8.

41. Chui KK, Cohen SA, Naumova EN. Snowbirds and infection--new phenomena in pneumonia and influenza hospitalizations from winter migration of older adults: a spatiotemporal analysis. BMC Public Health. 2011;11:444.

42. Constant AF, Zimmermann KF. Circular and repeat migration: counts of exits and years away from the host country. Popul Res Policy Rev. 2011;30(4): 495-515.

43. Gushulak BD, Pottie K, Hatcher Roberts J, Torres S, DesMeules M, Canadian Collaboration for I, Refugee H. Migration and health in Canada: health in the global village. CMAJ. 2011;183(12):E952-8.

44. Davies AA, Borland RM, Blake C, West HE. The dynamics of health and return migration. PLOS Med. 2011;8(6):e1001046.

45. Vertovec S. Migrant transnationalism and modes of transformation. Int Migr Rev. 2004;38(3):970-1001.

46. Takenaka A. Secondary migration: who re-migrates and why these migrants matter. Migr Inf Source. 2007;26. https://www.migrationpolicy.org/article/ secondary-migration-who-re-migrates-and-why-these-migrants-matter.

47. Solar O, Irwin A. A conceptual framework for action on the social determinants of health. In. Geneva: World Health Organization; 2010.

48. Bell M, Charles-Edwards E, Ueffing P, Stillwell J, Kupiszewski M, Kupiszewska D. Internal migration and development: comparing migration intensities around the world. Popul Dev Rev. 2015;41(1):33-58.

49. Bell M, Ward G. Comparing temporary mobility with permanent migration. Tour Geogr. 2000;2(1):87-107.

50. International Organization for Migration. World Migration Report 2011 : Communicating Effectively about Migration. In: International Organization for Migration; 2011.

51. Downs SH, Black N. The feasibility of creating a checklist for the assessment of the methodological quality both of randomised and non-randomised studies of health care interventions. J Epidemiol Community Health. 1998; 52(6):377-84.

52. Von Elm E, Altman DG, Egger M, Pocock SJ, Gøtzsche PC, Vandenbroucke $J P$, Initiative $S$. The strengthening the reporting of observational studies in epidemiology (STROBE) statement: guidelines for reporting observational studies. Prev Med. 2007;45(4):247-51.

53. Aguila EE. Jose; Leng, Mei; Morales, Leo: health status and behavioral risk factors in older adult Mexicans and Mexican immigrants to the United States. Journal of Aging and Health. 2013;25(1):136-58.

54. Castaneda SF, Rosenbaum RP, Holscher JT, Madanat H, Talavera GA. Cardiovascular disease risk factors among latino migrant and seasonal farmworkers. Journal of Agromedicine. 2015;20(2):95-104.

55. Castaneda, SF, Rosenbaum RP, Gonzalez P, Holscher JT. Breast and cervical cancer screening among rural midwestern Latina migrant and seasonal farmworkers. J Prim Care Community Health. 2012;3(2):104-10.

56. Knoff JSH, Harlow SD, Yassine M, Soliman AS. Cervical cancer screening practice and knowledge among Hispanic migrant and seasonal farmworkers of Michigan. J Prim Care Community Health. 2013;4(3):209-15.

57. Kristensen $P B, T$. Dealing with emigration in cohort studies: follow-up of mortality and cancer incidence among Norwegians born between 1967 and 1976. Eur J Epidemiol. 2010;25(3):155-61.
58. McGorrian CD, Daly L, Fitzpatrick P, Moore RG, Turner J, Kelleher CC. AllIreland Traveller health study, team: cardiovascular disease and risk factors in an indigenous minority population. The all-Ireland Traveller health study. Eur J Prev Cardiolog. 2012;19(6):1444-53.

59. Mocellin JF, P. Health status and geographic mobility among semi-nomadic pastoralists in Mongolia. Health Place. 2008;14(2):228-42.

60. Parry G, Van Cleemput P, Peters J, Walters S, Thomas K, Cooper C. Health status of Gypsies and Travellers in England. [Erratum appears in J Epidemiol Community Health. 2007 Jun;61(6):559]. J Epidemiol Community Health. 2007;61(3):198-204.

61. Peters JP, Parry GD, Van Cleemput P, Moore J, Cooper CL, Walters SJ. Health and use of health services: a comparison between gypsies and Travellers and other ethnic groups. Ethnicity Health. 2009;14(4):359-77.

62. Riosmena F, Wong R, Palloni A. Migration selection, protection, and acculturation in health: a binational perspective on older adults. Demography. 2013;50(3):1039-64

63. Wong WC, Wun YT, Chan KW, Liu Y. Silent killer of the night: a feasibility study of an outreach well-women clinic for cervical cancer screening in female sex workers in Hong Kong. Int J Gynecol Cancer. 2008;18(1):110-5.

64. Burchard EG, Ziv E, Coyle N, Gomez SL, Tang H, Karter AJ, Mountain JL, PérezStable EJ, Sheppard D, Risch N. The importance of race and ethnic background in biomedical research and clinical practice. In: Mass Medical Soc. 2003.

65. Messias DH. Transnational health resources, practices, and perspectives: Brazilian immigrant Women's narratives. J Immigr Health. 2002;4(4):183-200.

66. Murphy EJ, Mahalingam R. Transnational ties and mental health of Caribbean immigrants. J Immigr Health. 2004;6(4):167-78.

67. Gastaldo D, Gooden A, Massaquoi N. Transnational health promotion: social well-being across borders and immigrant women's subjectivities. Wagadu. 2005 May 21;2(1):1-6.

68. Villa-Torres L, González-Vázquez T, Fleming PJ, González-González EL, Infante-Xibille C, Chavez R, Barrington C. Transnationalism and health: A systematic literature review on the use of transnationalism in the study of the health practices and behaviors of migrants. Soc Sci Med. 2017;183:70-9.

69. Ryan L, D'Angelo A. Changing times: migrants' social network analysis and the challenges of longitudinal research. Soc Netw. 2018;53:148-58.

70. Ryan L. Migrants' social networks and weak ties: accessing resources and constructing relationships post-migration. Sociol Rev. 2011;59(4):707-24.

71. Molina JL, Valenzuela-Garía H, Lubbers MJ, García-Macías A, Pampalona J: Looking Inside the Ethnic Enclave: Inequality, Social Capital and Transnationalism. In: Migrant Capital: Networks, Identities and Strategies. Edited by Ryan L, Erel U, D’Angelo A. London: Palgrave Macmillan UK; 2015: 154-171.

72. Graeme H. Circular migration: keeping development rolling. Washington, DC: Migration Policy Institute; 2003. https://www.migrationpolicy.org/article/ circular-migration-keeping-development-rolling.

73. Glinos IA, Baeten R: A literature review of cross-border patient mobility in the European Union. In. Edited by Project EfP; 2006.

74. Glinos IA, Baeten R, Helble M, Maarse H. A typology of cross-border patient mobility. Health \& place. 2010;16(6):1145-55.

75. Rees P, Bell M, Duke-Williams O, Blake M. Problems and solutions in the measurement of migration intensities: Australia and Britain compared. Popul Stud. 2000;54(2):207-22.

76. Source: International Organization for Migration, Glossary on Migration, International Migration Law Series No. 25, 2011. https://www.iom.int/keymigration-terms.

77. Gushulak BD, Weekers J, MacPherson DW. Migrants and emerging public health issues in a globalized world: threats, risks and challenges, an evidence-based framework. Emerging Health Threats Journal. 2009;2:e10.

78. Castañeda H, Kline N, Dickey N. Health concerns of migrant backstretch workers at horse racetracks. J Health Care Poor Underserved. 2010;21(2):489-503.

79. Emmi KE, Jurkowski JM, Codru N, Bell EM, Kacica MA, Carter TP. Assessing the health of migrant and seasonal farmworkers in New York state: statewide data 2003-2005. J Health Care Poor Underserved. 2010;21(2):448-63.

80. González-Block MA, de la Sierra-de LA: Hospital utilization by Mexican migrants returning to Mexico due to health needs. BMC Public Health. 2011;11(1):1.

81. Aghasadeghi K, Zarei-Nezhad M, Keshavarzi A, Mehrabani D. The prevalence of coronary risk factors in Iranian lor migrating tribe. Arch Iran Med. 2008; 11(3):322-5.

82. Grappasonni I, Petrelli F, Amenta F. Deaths on board ships assisted by the Centro Internazionale radio medico in the last 25 years. Travel Med Infect Dis. 2012;10(4):186-91. 
83. Briand G, Peters R. Community perspectives on cultural considerations for breast and cervical cancer education among Marshallese women in Orange County, California. Calif J Health Promot. 2010;8:6.

84. Rechel BM, Mladovsky P, Ingleby D, Mackenbach JP, McKee M. Migration and health in an increasingly diverse Europe. Lancet. 2013;381(9873):1235-45.

85. Allen W. "I am from Busia!": everyday trading and health service provision at the Kenya-Uganda border as place-making activities. J Borderlands Studies. 2013;28(3):291-306.

86. Thomas KJA. Return migration in Africa and the relationship between educational attainment and labor market success: evidence from Uganda. Int Migr Rev. 2008;42(3):652-74

87. Zhu L, Qin M, Du L, Jia W, Yang Q, Walker M, Wen S. Comparison of maternal mortality between migrating population and permanent residents in Shanghai, China, 1996-2005. BJOG Int J Obstet Gynaecol. 2009;116(3):401-7.

88. Holguin F, Moughrabieh MA, Ojeda V, Patel SR, Peyrani P, Pinedo M, Celedón JC, Douglas IS, Upson DJ, Roman J. Respiratory health in migrant populations: a crisis overlooked. Ann Am Thoracic Soc. 2017;14(2):153-9.

89. Spallek J, Zeeb H, Razum O. What do we have to know from migrants' past exposures to understand their health status? A life course approach. Emerging Themes Epidemiol. 2011;8(1):6.

90. Findlay A, McCollum D, Coulter R, Gayle V. New mobilities across the life course: A framework for analysing demographically linked drivers of migration. Popul Space Place. 2015;21(4):390-402.

91. Mainil T. Medical sociology as a heuristic instrument for medical tourism and cross-border healthcare: comment on "international patients on operation vacation - perspectives of patients travelling to Hungary for orthopedic treatments". Int J Health Policy Manag. 2015;4(4):243-4.

92. Dayes IS, Whelan TJ, Julian JA, Kuettel MR, Regmi D, Okawara GS, Patel M, Reiter HI, Dubois S. Cross-border referral for early breast cancer: an analysis of radiation fractionation patterns. Curr Oncol. 2006;13(4):124-9.

93. Di lorio CT, Carinci F, Brillante M, Azzopardi J, Beck P, Bratina N, Cunningham SG, De Beaufort C, Debacker N, Jarosz-Chobot P, et al. Crossborder flow of health information: is 'privacy by design' enough? Privacy performance assessment in EUBIROD. Eur J Pub Health. 2013;23(2):247-53.

Ready to submit your research? Choose BMC and benefit from:

- fast, convenient online submission

- thorough peer review by experienced researchers in your field

- rapid publication on acceptance

- support for research data, including large and complex data types

- gold Open Access which fosters wider collaboration and increased citations

- maximum visibility for your research: over $100 \mathrm{M}$ website views per year

At $\mathrm{BMC}$, research is always in progress.

Learn more biomedcentral.com/submissions 